\title{
Pengaruh Kualitas Pelayanan Terhadap Kepuasan Deposan Pada BPR KS Cabang Kiaracondong
}

\author{
Tatang Suhidayat \\ Program Studi Manajemen \\ Sekolah Tinggi Ilmu Ekonomi STAN IM, Jl. Belitung No.7 Bandung \\ Email : tatangherisman9@gmail.com
}

\begin{abstract}
ABSTRAK
Pengaruh Kualitas Pelayanan Terhadap Kepuasan Deposan (Suatu Kasus Pada BPR KS Cabang Kiaracondong). Penelitian ini dilakukan untuk menguji pengaruh kualitas pelayanan terhadap kepuasan deposan yang dilakukan di BPR KS dengan memanfaatkan lima dimensi kualitas pelayanan (servqual) yaitu reliability, responsiveness, assurance, emphaty dan tangible, melalui pengamatan, wawancara serta mempergunakan instrumen pengumpulan data berupa kuesioner tertutup.

Sampel dipilih dengan metode accidental/convinience sampling, dengan ukuran sample 100 responden. Analisis regresi berganda digunakan untuk pengujian hipotesis adanya pengaruh 5 dimensi terhadap kepuasan deposan. Hasil penelitian menunjukkan bahwa program-program peningkatan kualitas pelayanan yang dilakukan oleh Bank BPR KS Cabang Kiaracondong ternyata mampu mempengaruhi kepuasan deposan.

Hasil penelitian menunjukkan bahwa secara simultan (bersama-sama) kelima dimensi kualitas jasa yaitu reliability, responsiveness, assurance, emphaty dan tangible mampu mempengaruhi kepuasan deposan secara signifikan. Secara terpisah (parsial) hanya dimensi reliability, empathy dan tangible yang mempunyai pengaruh signifikan terhadap peningkatan kepuasan deposan.
\end{abstract}

Kata Kunci : Kualitas Pelayanan, Kepuasan Deposan, Metode Accidental.

\section{ABSTRACT}

The Effect of Service Quality on Depositor Satisfaction (A Case At BPR KS Kiaracondong Branch). This study was undertaken at BPR KS to investigate the impact of service quality on depositor satisfaction, employing five aspects of service quality (servqual), including reliability, responsiveness, assurance, empathy, and tangibles, as well as observation, interviews, and data collection instruments in the form of closed questionnaires.

With a sample size of 100 respondents, the sample was chosen using the accidental/convenience sampling method. The hypothesis of the influence of five dimensions on depositor satisfaction was tested using multiple regression analysis. The results showed that the service quality improvement programs carried out by BPR KS Kiaracondong Branch were able to affect depositor satisfaction.

The results showed that simultaneously (together) the five dimensions of service quality, namely reliability, responsiveness, assurance, empathy and tangibles were able to significantly affect depositor satisfaction. Separately (partial) only the dimensions of 
reliability, empathy and tangible have a significant influence on increasing depositor satisfaction.

Keywords: Service Quality, Depositor Satisfaction, Accidental Method.

\section{PENDAHULUAN}

Perkembangan industri perbankan saat ini, khususnya di Indonesia, sekarang mempunyai korelasi positif dengan kondisi perekonomian secara umum. Dengan demikian, industri perbankan sebagai financial intermediary institution yang menjembatani antara surplus unit dengan defisit unit merupakan salah satu kunci atau barometer yang menggambarkan maju mundurnya perekonomian negara.

Begitu pentingnya peranan industri perbankan sebagai salah satu komponen pemacu perekonomian, maka telah menjadi suatu tuntunan bahwa pengelolaan bank memerlukan ketangguhan manajemen yang dapat mengendalikan jalannya aktifitas bank dalam berbagai kondisi perekonomian. Banyak faktor yang dapat mempengaruhi kepuasan nasabah untuk tetap konsisten menjadi bank mainded dan salah satunya adalah Kualitas Pelayanan.

Suatu hal yang harus dipahami bahwa baiknya kualitas pelayanan dan efektifnya dalam melakukan bauran promosi akan memberikan respon positf terhadap kepuasan nasabah bank untuk tetap loyal menggunakan jasanya. Menurut (Goncalves, Karen P., 1998) menerangkan bahwa pada dasarnya tujuan suatu bisnis adalah untuk menciptakan para pelanggan yang merasa puas. Terciptanya kepuasan pelanggan dapat memberikan beberapa manfaat, diantaranya hubungan antara perusahaan dan pelanggan menjadi harmonis, memberikan dasar yang baik bagi pembelian ulang dan terciptanya loyalitas pelanggan dan membentuk rekomendasi dari mulut ke mulut (word of mouth) yang menguntungkan bagi perusahaan (Schnaars, 1998).

Salah satu faktor yang menentukan tingkat kepuasan kepada konsumen adalah kemampuan perusahaan dalam memberikan pelayanan kepada pelanggannya. Keberhasilan perusahaan dalam memberikan layanan yang bermutu kepada pelanggannya sangat ditentukan oleh pendekatan yang digunakan. Pendekatan kualitas pelayanan jasa yang dibangun atas adanya perbandingan dua faktor utama yaitu persepsi pelanggan atas layanan yang nyata mereka terima (perceived 
service) dengan layanan yang sesungguhnya diharapkan/diinginkan (expected service) akan menghasilkan tingkat kepuasan pelanggan.

Sementara itu Kepuasan adalah perasaan senang atau kecewa seseorang yang muncul setelah membandingkan antara persepsi/kesannya terhadap kinerja (atau hasil) suatu produk dengan harapan-harapannya (Kotler, 2000).

Pendapat di atas, memberikan arti bahwa eksistensi kualitas pelayanan yang baik, akan menjadi faktor pendorong untuk meningkatkan kepuasan nasabah dalam menempatkan dana di bank itu sendiri. Keadaan ini, tidak sejalan dengan informasi yang penulis peroleh bahwa tingkat kepuasan nasabah/deposan di BPR KS Cabang Kiaracondong tidak sesuai dengan harapan nasabah, sehingga selama selama 4 tahun berjalan yaitu Desember 2015 s/d Desember 2019 cenderung menurun untuk jumlah deposan dan meningkat untuk keluahan atas surat masuk.

Penyebab utama kondisi ini adalah kurang optimal atau tidak sesuainya harapan nasabah di bidang kualitas pelayanan yang diberikan. Berdasarkan fenomena ini, penulis merasa tertarik untuk mengetahui secara objektif yaitu seberapa besar tingkat kepuasan deposan atas kualitas pelayanan yang diberikan oleh bank tersebut.

Untuk lebih mengarah pada inti pokok bahasan skripsi ini, penulis mengidentifikasikan permasalahannya adalah sebagai berikut : 1). Bagaimana kualitas pelayanan jasa yang diberikan oleh BPR KS Cabang Kiaracondong, 2). Bagaimana tingkat kepuasan deposan sebagai nasabah di BPR KS Cabang Kiaracondong, 3). Sampai sejauhmana kualitas pelayanan jasa berpengaruh terhadap kepuasan deposan pada BPR KS Cabang Kiaracondong.

\section{METODE PENELITIAN}

Pada penelitian ini, peneliti melakukan pengamatan kepada nasabah BPR KS Cabang Kiaracondong yang berlokasi di Jl. Abdurahman Saleh No.2 Bandung. Metode yang digunakan dalam penelitian ini adalah metode penelitian deskriptif dengan pendekatan studi kasus. Penulis menggunakan metode penelitian deskriptif yaitu statistika yang digunakan untuk menganalisa data dengan cara mendeskripsikan atau menggambarkan data yang telah terkumpul sebagaimana adanya (Sugiyono, 2014).

Peneliti dan objek yang diteliti terpisah dan proses penelitian dilakukan melalui pengukuran dengan bantuan alat yang baku dan objektif hasil penelitian berupa generalisasi, yaitu kesimpulan umum yang dibuat atas dasar fakta empiris tentang sampel penelitiannya, 
sedangkan penelitian yang dilakukan mempunyai maksud memberikan penjelasan dengan cara melakukan pengukuran secara cermat terhadap, fenomena tertentu dan menjelaskan hubungan kausal antara variabel variabel melalui pengujian hipotesis.

Untuk penentuan sampel digunakan metode survey, yaitu penelitian yang mengambil sampel dari satu populasi dan menggunakan kuesioner sebagai alat pengumpulan data yang pokok (Singarimbun, 1995). Untuk ukuran sampel menggunakan rumus slovin, sehingga didapat sampel berjumlah 96 responden.

Teknik pengumpulan data dilakukan dengan cara 1). Obesrvasi Adalah suatu cara teknik pengumpulan data dimana penulis langsung mengadakan pengamatan (observasi) ke obyek penelitian yang sedang dibahas, yaitu pada BPR KS Cabang Kiaracondong. 2). Wawancara, Penulis melakukan wawancara langsung terhadap orang-orang yang dapat memberikan sejumlah bahan atau informasi khusus sebagai pelengkap yang diperlukan dalam rangka pengumpulan data. 3). Kuesioner, Angket atau kuesioner (Questionaire) merupakan suatu penyelidikan mengenai suatu masalah yang umumnya banyak menyangkut kepentingan umum (orang banyak), dilakukan dengan jalan mengedarkan suatu daftar pertanyaan berupa formulir-formulir, diajukan secara tertulis kepada sejumlah subyek untuk mendapatkan jawaban atau anggapan (respon) tertulis seperlunya.

Dalam Penelitian ini melakukan pendekatan Analisis Deskriptif dan Inferesial. Analisis statistik despriptif berfungsi untuk mendiskripsikan atau memberikan gambaran terhadap objek yang diteliti melalui data sample sebagaimana adanya, tanpa melakukan analisis dan membuat kesimpulan yang berlaku umum. Sedangkan statistik inferensial ditujukan untuk mengenalisa data yang difatnya non-parametris, sehingga dengan analisis ini dapat mengatahui hubungan dari variabel yang diteliti. Serta dilakukan pengujian Analisis Regresi Berganda, Uji F dan Uji t.

\section{HASIL DAN PEMBAHASAN}

Hasil penelitian tentang kondisi kualitas pelayanan jasa terhadap kepuasan deposan pada BPR KS Cabang Kiaracondong dan kemudian penulis melakukan pembahasan hasilnya tampak pada bahasan di bawah ini.

Berpatokan pada lima dimensi dalam mengukur kualitas pelayanan yang diberikan BPR KS di atas, maka untuk bila dilihat secara global tentang kondisi kualitas pela- 
yanan terhadap para deposan BPR KS Cabang Kiaracondong, dapat dilihat pada tabel dibawah ini.

Tabel 1. Rekapitulasi Jawaban Responden tentang Kualitas Pelayanan

\begin{tabular}{|c|c|c|c|c|c|c|c|c|c|c|c|}
\hline \multirow{3}{*}{ No } & \multirow{3}{*}{ Uraian } & \multirow{3}{*}{$\begin{array}{c}\text { Kutub } \\
1\end{array}$} & \multicolumn{5}{|c|}{ Penilaian Deposan } & \multirow{3}{*}{ Kutub 2} & \multirow{3}{*}{ Total } & \multirow{3}{*}{ Mean } & \multirow{3}{*}{$\begin{array}{l}\text { STANDAR } \\
\text { DEVIASI }\end{array}$} \\
\hline & & & TB & KB & $\mathrm{CB}$ & B & SB & & & & \\
\hline & & & 1 & 2 & 3 & 4 & 5 & & & & \\
\hline $\mathrm{X} 1$ & Realibilty (Keandalan) & $\begin{array}{l}\text { Tidak } \\
\text { Baik }\end{array}$ & 0 & 0 & 84 & 109 & 107 & $\begin{array}{l}\text { Sangat } \\
\text { Baik }\end{array}$ & 300 & 4.08 & 0.3345 \\
\hline $\mathrm{X} 2$ & $\begin{array}{c}\text { Responsiveness (Daya } \\
\text { Tanggap) }\end{array}$ & $\begin{array}{l}\text { Tidak } \\
\text { Baik }\end{array}$ & 0 & 0 & 57 & 76 & 67 & $\begin{array}{l}\text { Sangat } \\
\text { Baik }\end{array}$ & 200 & 4.05 & 0.5342 \\
\hline $\mathrm{X} 3$ & Asuurance (Jaminan) & $\begin{array}{l}\text { Tidak } \\
\text { Baik }\end{array}$ & 0 & 0 & 121 & 154 & 125 & $\begin{array}{l}\text { Sangat } \\
\text { Baik }\end{array}$ & 400 & 4.01 & 0.2273 \\
\hline $\mathrm{X} 4$ & Empaty (Empati) & $\begin{array}{l}\text { Tidak } \\
\text { Baik }\end{array}$ & 0 & 0 & 86 & 120 & 94 & $\begin{array}{l}\text { Sangat } \\
\text { Baik }\end{array}$ & 300 & 4.03 & 0.3146 \\
\hline $\mathrm{X} 5$ & $\begin{array}{l}\text { Tangibles (Fasilutas } \\
\text { Fisik) }\end{array}$ & $\begin{array}{l}\text { Tidak } \\
\text { Baik }\end{array}$ & 0 & 0 & 146 & 192 & 162 & $\begin{array}{l}\text { Sangat } \\
\text { Baik }\end{array}$ & 500 & 4.03 & 0.2322 \\
\hline & Rata- I & Rata Me & ean & $\operatorname{an} \mathrm{S}$ & dar 1 & evias & & & & 4.04 & 0.32856 \\
\hline
\end{tabular}

Sumber : Data Primer

Mengamati tabel 1 di atas, menunjukkan bahwa kualitas pelayanan di BPR KS Cabang Kiaracondong secara umum termasuk katagori BAIK, terlihat dari rara-rata nilai men mencapai 4,04 dengan standar deviasi 0,03286.

Pemantauan dan pengukuran terhadap kepuasan deposan telah menjadi hal yang sangat esensial bagi setiap BPR KS. Hal ini dikarenakan langkah tersebut dapat memberikan umpan balik dan masukan bagi keperluan pengembangan dan implementasi strategi peningkatan kepuasan deposan. Untuk mengukur kepuasan deposan ini, didasarkan pada survey kepuasan deposan sebagai nasabah. 
Tabel 2. Rekap Jawaban Responden tentang Kepuasan Deposan

\begin{tabular}{|c|c|c|c|c|c|c|c|c|c|c|c|}
\hline \multirow{3}{*}{ No } & \multirow{3}{*}{ Uraian } & \multirow{3}{*}{ Kutub 1} & \multicolumn{5}{|c|}{ Penilaian Deposan } & \multirow{3}{*}{ Kutub 2} & \multirow{3}{*}{\multicolumn{2}{|c|}{ Total Mean }} & \multirow{3}{*}{$\begin{array}{l}\text { Standar } \\
\text { Deviasi }\end{array}$} \\
\hline & & & \multirow{2}{*}{$\frac{\text { TP }}{1}$} & \multirow{2}{*}{$\frac{\mathrm{KP}}{2}$} & \multirow{2}{*}{$\frac{\mathbf{C P}}{3}$} & \multirow{2}{*}{$\begin{array}{l}P \\
4\end{array}$} & \multirow{2}{*}{$\frac{\text { SP }}{5}$} & & & & \\
\hline & & & & & & & & & & & \\
\hline 18 & $\begin{array}{c}\text { Service dari } \\
\text { berbagai bagian } \\
\text { secara umum }\end{array}$ & $\begin{array}{l}\text { Sangat men- } \\
\text { gecewakan }\end{array}$ & 0 & 0 & 44 & 46 & 10 & $\begin{array}{l}\text { Sangat } \\
\text { memuaskan }\end{array}$ & 100 & 3.66 & 0.6547 \\
\hline 19 & $\begin{array}{l}\text { Kualitas kerja } \\
\text { teller secara umum }\end{array}$ & $\begin{array}{l}\text { Sangat men- } \\
\text { gecewakan }\end{array}$ & 0 & 0 & 38 & 43 & 19 & $\begin{array}{c}\text { Sangat } \\
\text { memuaskan }\end{array}$ & 100 & 3.81 & 0.7344 \\
\hline 20 & $\begin{array}{c}\text { Kerja teller di } \\
\text { banding harapan } \\
\text { yang ada pada } \\
\text { deposan }\end{array}$ & $\begin{array}{l}\text { Sangat men- } \\
\text { gecewakan }\end{array}$ & 0 & 0 & 22 & 36 & 42 & $\begin{array}{l}\text { Sangat } \\
\text { memuaskan }\end{array}$ & 100 & 4.2 & 0.7785 \\
\hline & $\begin{array}{l}\text { Perlakukan kerja } \\
\text { teller dibanding } \\
\text { harapan pd } \\
\text { deposan }\end{array}$ & $\begin{array}{l}\text { Sangat men- } \\
\text { gecewakan }\end{array}$ & 0 & 0 & 15 & 46 & 39 & $\begin{array}{c}\text { Sangat } \\
\text { memuaskan }\end{array}$ & 100 & 4.24 & 0.6981 \\
\hline 22 & $\begin{array}{l}\text { Cara kerja custom- } \\
\text { er service }\end{array}$ & $\begin{array}{l}\text { Sangat men- } \\
\text { gecewakan }\end{array}$ & 0 & 0 & 38 & 43 & 19 & $\begin{array}{c}\text { Sangat } \\
\text { memuaskan }\end{array}$ & 100 & 3.81 & 0.7344 \\
\hline 23 & Cara kerja Satpam & $\begin{array}{c}\text { Sangat men- } \\
\text { gecewakan }\end{array}$ & 0 & 0 & 30 & 34 & 36 & $\begin{array}{c}\text { Sangat } \\
\text { memuaskan }\end{array}$ & 100 & 4.06 & 0.8143 \\
\hline 24 & $\begin{array}{l}\text { Putusan } \\
\text { menggunakan } \\
\text { bank }\end{array}$ & $\begin{array}{l}\text { Sangat me- } \\
\text { nyesal }\end{array}$ & 0 & 0 & 38 & 43 & 19 & $\begin{array}{l}\text { Sangat me- } \\
\text { nyenangkan }\end{array}$ & 100 & 3.81 & 0.7344 \\
\hline 25 & $\begin{array}{l}\text { Rekomendasi ke } \\
\text { teman / saudara }\end{array}$ & Dilarang keras & 0 & 0 & 37 & 31 & 32 & $\begin{array}{l}\text { Sangat di- } \\
\text { anjurkan }\end{array}$ & 100 & 3.96 & 0.8519 \\
\hline 26 & $\begin{array}{l}\text { Feeling service } \\
\text { bank kedepan }\end{array}$ & $\begin{array}{l}\text { Sangat ter- } \\
\text { buruk }\end{array}$ & 0 & 0 & 50 & 31 & 19 & Sangat terbaik & 100 & 3.69 & 0.7745 \\
\hline & & & Rata & Rata $N$ & & & & & & 3.9156 & 0.7528 \\
\hline
\end{tabular}

Sumber : Data Primer

Mengamati tabel 2 di atas, memberikan gambaran bahwa tingkat kepuasan deposan atas pelayanan yang diberikan secara umum termasuk katagori CUKUP PUAS, terlihat dari nilai mean rara-rata mencapai 3,9156 dengan standardeviasi 0,7528. Arti semua ini bahwa bila diasumsikan tingkat harapan deposan adalah 5 (lima), maka tingkat kepuasan deposan telah mencapai 78,31\% (diperoleh dari 3,9156 dibagi 5 dikalikan $100 \%)$, sehingga masih terdapat Gap sebasar 21,69\%.

Berdasarkan hasil penghitungan regresi dan koleasi ganda, tampak pada tabel di bawah ini. 
Tabel 3. Hasil Uji t

\begin{tabular}{|c|c|c|c|c|c|c|}
\hline \multirow[t]{2}{*}{ No } & \multirow[t]{2}{*}{ Model } & \multicolumn{2}{|c|}{$\begin{array}{l}\text { Unstandardized Coeffi- } \\
\text { cients }\end{array}$} & \multirow{2}{*}{$\begin{array}{c}\begin{array}{c}\text { Standardized } \\
\text { Coefficients }\end{array} \\
\text { Beta }\end{array}$} & \multirow[t]{2}{*}{$\mathbf{t}$} & \multirow[t]{2}{*}{ Sig. } \\
\hline & & B & Std. Error & & & \\
\hline \multirow[t]{6}{*}{1} & (Constant) & $(17.4810)$ & 7.4472 & & $(2.3473)$ & 0.0210 \\
\hline & X1 (reliability) & 0.5440 & 0.2561 & 0.1694 & 2.1241 & 0.0363 \\
\hline & X2 (responsivenes) & 1.2575 & 0.2369 & 0.4169 & 5.3071 & 0.0000 \\
\hline & X3 (asurance) & 0.4832 & 0.2756 & 0.1363 & 1.7533 & 0.0828 \\
\hline & X4 (emphaty) & 0.8326 & 0.2673 & 0.2438 & 3.1144 & 0.0024 \\
\hline & X5 (tangible) & 0.8961 & 0.2160 & 0.3228 & 4.1497 & 0.0001 \\
\hline
\end{tabular}

Sumber : Data Primer

Pada tabel di atas dapat dilihat bahwa nilai t hitung yang melebihi t tabel $(=1,98)$ untuk derajat bebas (94) dan level signifikansi 0,05 berlaku untuk variabel Constant $\mathrm{X} 1, \mathrm{X} 2, \mathrm{X} 3, \mathrm{X} 4$ dan $\mathrm{X}_{5}$. Maka dapat diambil kesimpulan bahwa varians yang terjadi pada variabel terikat $\mathrm{Y}$ ditentukan secara signifikan hanya oleh varians yang ada pada variabel bebas $\mathrm{X}_{1}, \mathrm{X} 2, \mathrm{X} 3, \mathrm{X}_{4}$, dan $\mathrm{X}_{5}$. Hal ini memiliki arti bahwa secara parsial varians yang terjadi pada kepuasan deposan/nasabah ditentukan secara signifikan oleh varians yang ada pads variabel reliability, responsiveness, assurance, emphaty dan tangible.

Tabel 4. Hasil Uji F

\begin{tabular}{|c|c|c|c|c|c|c|}
\hline Model & & Sum of Squares & df & Mean Square & $\mathrm{F}$ & Sig. \\
\hline \multirow{3}{*}{1} & Regression & 455.719 & 5 & 91.144 & 14.965 & $.000^{\mathrm{b}}$ \\
\hline & Residual & 572.521 & 94 & 6.091 & & \\
\hline & Total & $1,028.240$ & 99 & & & \\
\hline
\end{tabular}

Pada tabel diatas dapat dilihat bahwa nilai $\mathrm{F}$ hitung $=14,9650$ jauh melebihi $\mathrm{F}$ tabel $=2,36$ untuk derajat bebas 5,94 dan level signifikansi $5 \%$. Karena F hitung lebih besar dari $\mathrm{F}$ tabel, maka variabel-variabel bebas (X1 s/d X5) secara simultan mempunyai pengaruh yang signifikan terhadap variabel terikat $\mathrm{Y}$. Hal ini memiliki makna bahwa variabel-variabel reliability, responsiveness, assurance, emphaty dan tangible secara simultan mempunyai pengaruh yang signifikan terhadap kepuasan nasabah. Secara simultan bahwa dimensi reliability, responsiveness, assurance, 
empathy dan tangible mempunyai pengaruh yang signifikan terhadap pemenuhan kepuasan deposan yang dibuktikan melalui uji $\mathrm{F}$, dengan tingkat signifikan 5\% atau tingkat kepercayaan $95 \%$.

Tabel 5. Koefisien Determinasi

\begin{tabular}{lcccc}
\hline Model & $\mathrm{R}$ & R Square & $\begin{array}{c}\text { Adjusted R } \\
\text { Square }\end{array}$ & $\begin{array}{c}\text { Std. Error of the } \\
\text { Estimate }\end{array}$ \\
\hline 1 & $.666^{\mathrm{a}}$ & .443 & .414 & 2.46792 \\
\hline Sumber : Data Primer & & &
\end{tabular}

Dengan menggunakan alat analisis SPSS yang tampak pada tabel di atas, maka diperoleh persamaan regresi linear berganda sebegai berikut :

$$
Y=-17,04810+0,5440 X 1+1,2575 X 2+0,4832 X 3+0,8326 X 4+0,8961 X 5
$$

Dengan nilai multiple correlation 0.6630 mengandung makna bahwa keseluruhan variabel bebas memiliki keeratan hubungan dengan variable terikat sebesar 66,3\%. Sedangkan koefesien determinasi (R2) sebesar 0.4430 yang memiliki makna bahwa 44,3\% kemampuan model atau seluruh variable bebas yang digunakan dalam persamaan regresi ini secara bersama-sama mampu memberikan konstribusi terhadap kepuasan deposan/nasabah. Sedangkan sisanya sebesar 55,7 \% dijelaskan oleh variable independen yang berada di luar penelitian ini.

\section{SIMPULAN}

Berdasarkan hasil penelitian dan pembahasan atas identifikasi masalah yang penulis tetapkan, dapat disimpulkan sebagai berikut : 1). Kondisi kualitas pelayanan pada BPR KS Cabang Kiaracondong menunjukkan bahwa kualitas pelayanan di bank tersebut termasuk katagori BAIK, terlihat dari rara-rata nilai men mencapai 4,04 dengan standar deviasi 0,03286. 2). Kondisi Tingkat Kepuasan Deposan pada BPR KS Cabang Kiaracondong, bahwa tingkat kepuasan deposan atas pelayanan yang diberikan secara umum termasuk katagori CUKUP PUAS, terlihat dari nilai mean rara-rata mencapai 3,9156 dengan standardeviasi 0,7528. Arti semua ini bahwa bila diasumsikan tingkat harapan deposan adalah 5 (lima), maka tingkat kepuasan deposan telah mencapai 78,31 \% (diperoleh dari 3,9156 dibagi 5 dikalikan $100 \%$ ), sehingga masih terdapat Gap sebasar 21,69\%.3). Pengaruh kualitas pelayanan terhadap kepuasan deposan pada BPR KS Cabang Kiaracondong, menunjukkan bahwa Hubungan antara variabel-variabel 
pada 5 (lima) dimensi kualitas pelayanan (realiability; responsiveness; assurance; empathy dan tangible) yang secara individu (parsial) dengan tingkat kepuasan deposan, memiliki hubungan positif dan kuat, tebukti dari hasil perhitungan korelasi didapat angka positif sebesar 0,663 yang hampir mendekati angka 1. Artinya bahwa kualitas pelayanan yang secara bersama dipengaruhi oleh realiability; responsiveness; assurance; empathy dan tangible, terdapat hubungan yang saling mempengaruhi dengan tingkat kepuasan deposan, sehingga apabila kualitas pelayanan yang dilihat dilihat dari lima dimensi itu ditingkatkan, maka kepuasan deposan akan meningkat, kecuali untuk veriabel assurance tidak terdapat hubungan yang signifikan pada tingkat signifikasi $5 \%$. Sementara itu dari hasil perhitungan menunjukkan bahwa nilai $\mathrm{F}$ hitung $=14,9650$ jauh melebihi $\mathrm{F}$ tabel = 2,36 untuk derajat bebas 5,94 dan level signifikansi $5 \%$. Karena $\mathrm{F}$ hitung lebih besar dari F tabel, maka variabel-variabel bebas (X1 s/d X5) secara simultan mempunyai pengaruh yang signifikan terhadap variabel terikat Y. Hal ini memiliki makna bahwa variabel-variabel reliability, responsiveness, assurance, emphaty dan tangible secara simultan mempunyai pengaruh yang signifikan terhadap kepuasan nasabah.

\section{DAFTAR PUSTAKA}

Goncalves, Karen P. (1998) Services Marketing; A Strategic Approach. New Jersey: Prentice Hall.

Kotler, P. (2000) Marketing Management. New Jersey: Prentice Hall.

Schnaars, S. . (1998) Marketing Strategy : A Customer Driven Approach. New York: The Free Press.

Singarimbun, Asri (1995) Metode penelitian dan Survey. Jakarta: LP3ES.

Sugiyono (2014) Metode Penelitian Kuantitatif Kualitatif dan R\&D. Bandung: CV. Alfabeta. 